\title{
Double-scope blending of associative and causal event structures in narratives
}

\section{Bartosz Stopel}

University of Silesia in Katowice, Poland

\begin{abstract}
The article explores the role of Turner's double-scope blending theory for the cognition and emotional response to narratives. I argue that narratives expected to afford aesthetic experience typically have a unified associative event structure, apart from the basic causal event structure, and that the former operates chiefly according to principles of similarity, thus being closer to metaphor than the latter. Double-scope blending seems to be essential to link narrative events associatively and then to blend this structure with the causal one, leading in effect to the complete, unified narrative. Thus, beyond its cognitive utility, it does seem to contain an important affective component which plays a role in aesthetic experience of stories.
\end{abstract}

Keywords: double-scope blending, narrative, causality, emotion, metaphor

\section{Introduction}

According to the theoretical framework developed by Gilles Fauconnier and Mark Turner, conceptual integration is a fundamental cognitive operation that underlies the emergence of language and complex thought processes. Turner calls it "a fundamental instrument of the everyday mind, used in our basic construal of all our realities, from the social to the scientific" (1996, p. 93). Simply speaking, conceptual integration, or blending, involves merging data from two separate input sources by means of tracking similarities and analogies in a process of projection (Turner, 2008, pp. 1-2), which are then compressed into one, new emergent structure. This is a process reminiscent of two projectors displaying different images on a wall in a parallel manner which are then brought together producing one image (Turner, 2008, p. 3). Or in a conversational context, to say that one wishes to avoid discussing certain topics as they are minefields is a clear example of a compressed blend emerging out of two inputs: the image of actual minefields and its dangers and a troublesome conversation (Schneider, 2012, pp. 7-8). 
Turner sees the basic operation of projection, responsible for "making various kinds of mental connections" (2008, pp. 1-2) as prerequisite for blending, the fully developed conceptual integration, whose most advanced form is double-scope blending, which he considers uniquely human, though widespread and pervasive in language and thought. Double-scope blending involves bringing together two incompatible domains, those which "conflict in radical ways on vital conceptual relations, such as cause-effect, modality, participant structure, role-value, and so on," (Fauconnier, Turner, 2008, p. 520) such as when we are constructing or construing a story involving talking animals. The blend is made of human and animal features which are clearly in conflict, yet they pose no cognitive challenge. In fact, Turner claims, such operations are effortless, widespread and fundamental for human cognition.

Quite naturally, blending theory has attracted scholars from areas such as cognitive science and linguistics. In terms of literary studies, meaning construction, metaphor and figurative language, poetics and stylistics have used it quite extensively. Narrative studies have not taken up blending theory in any prominent sense, as observed by Ralph Schneider in the introduction to one of the few works on the topic (Schneider, Hartner, 2012) even though Turner emphasizes the centrality of double-scope blending for narrative cognition from the very beginning of formulating its theory. Given the high level of fragmentation of narratology nowadays and the long struggle to overcome the totalizing tendencies of structuralism, perhaps narrative scholars are distrustful of any approach that makes grand and very general claims about stories. Or perhaps it was the fact that narratology was already an established discipline before the arrival of Turner's work and many of the sub-fields within it can operate virtually unaffected by the notion of blending. Whatever the answer, rather than exploring Turner's putative and overarching claims about stories, in what follows I will focus on one issue which I believe has not been adequately named and described by either narratologists, or cognitive scientists, or blending theorists but which I believe is crucial for understanding appreciation of narrative art (apart from making some minor points about stories in general) and which involves double-scope blending. To put it simply, I believe some central aesthetic expectations we routinely have chiefly (but not necessarily exclusively) about the structure of fictional narratives include the assumption that narrative artworks are or should be unified in a way that goes beyond standard cause-effect event chains or their general thematic relevance. Such unity of narrative art involves basic form/content connection, and in terms of event structures, this means deeper, non-causal, associational, metaphorical interconnectedness of whatever happens in a story. But if part of standard aesthetic expectations about stories (and about art in general, as a matter of fact) is that they are associatively unified, this means that they invite readers or audiences to construe them as do- 
uble-scope blends where cause-effect event progression blends with their associative connections into a complete artwork. Still simpler, cognition of any kind of art involves constructing an associational double-scope blend, yet I believe this has not been adequately named in terms of event progression in narratives. In what follows, I wish to develop my argument.

\section{Conceptual blending}

From the very beginning of his research, Turner's focus has been on the cognitive importance of stories. In The Literary Mind, he stated that story, or "narrative imagining is the fundamental instrument of thought. Rational capacities depend on it. It is our chief means of looking into the future, of predicting, of planning, and of explaining." (Turner, 1996, pp. 4-5). This basic instrument of thought can be further developed by means of projecting one story onto another, creating an allegorical meta-story that gives us indirect and often more accessible or more imaginative way of conceptualizing a lower level story including the fundamental concept, problem or question which was supposed to be cognized with the help of the latter story. This allegorical meta-story is of course the ancient parable or fable, as illustrated by Turner in the example of a tale of an ox and a donkey told to Scheherazade by her father as piece of advice. Parables are not restricted to literary narratives and thus Turner argues, proverbs are typically compressed narratives which are supposed to be interpreted by means of projection, as in "when the cat's away, the mice will play."

In his discussion of parable, Turner enumerates what he calls mental patterns, the cognitive actions and capacities associated with the projection of the story. They include the simulation-like processes of prediction, evaluation, planning and explanation, where we explore the sources and reasons behind certain actions and events, as well as imagine possible outcomes and assess them, thus helping to shape and specify our own goals and plans. Moreover, stories help us to conceptualize events, actors and objects. They also exploit our tendency to think in terms of emblems (or prototypes) and exempla, metonymies and analogies between the real and the imaginative world. The latter tendency leads to one particularly important process pertaining to human cognitive skills, namely, to conceptual blending, the process of finding connections between seemingly unrelated concepts or events and then producing a new, emergent structure.

Blending is a process composed of three major stages. Its first stage involves mapping: looking for connections in space, time, causality, identity, similarity, etc. between two or more structures. Next, one selectively projects aspects of one 
concept/story onto the other and finally, a new emergent structure is created. In his words, "the essence of the operation is to construct a partial match between two inputs, to project selectively from those inputs into a novel 'blended' mental space, which then dynamically develops emergent structure" (Fauconnier, Turner, 2003, pp. 57-58). In one famous example Turner and Fauconnier mention a modern catamaran is sailing in 1993 to Boston from San Francisco attempting to move faster than a ship that sailed the same course 150 years earlier. The sailing magazine reporting the "race" commented as if the two were actually competing stating that at one point the catamaran had a "4.5 day lead over the ghost of the clipper" (Fauconnier, Turner, 2003, pp. 58-59). There are, then, two events clearly separated in time, entailing two distinct mental spaces blended together into one race by mapping, selecting some analogies (the voyage, the departure and arrival points, the period and time of travel, the boat, its positions at various times) and projecting them into a new space. Turner calls this type of blend mirror network where "two input spaces share topology given by an organizing frame, and the blend inherits that organizing frame" (Turner, 2008, p. 4). The blend in the end is framed as "two boats making ocean voyages and moreover racing as they make them" (Turner, 2008, p. 4). This is one of the simple types of blends, along with the simplex network where, to use Turner's example, one introduces John as the father of James, which results in a simple blend of two inputs: John and the parent role (Turner, 2008, p. 4).

The use of blends is overwhelmingly vast and might include mundane everyday operations such as drawing analogies between one's casual bus ride and another one taken some time ago, or everyday use of prevalent metaphorical expressions (e.g. calling someone a bookworm involves mapping analogies between ardent book reading and physically consuming them as an insect, then partially projecting those analogies onto a newly emerging structure containing the bookworm blend), as well as standard operations carried out in experiencing art (reading Joyce's Ulysses and looking for parallels with the mythical story produces a blended space) and in politics, religion and other areas of life.

There is also one particular type of blends that Turner discusses which appears to involve an unusual degree of creativity, that is, the double-scope blend. It is the most advanced type of blending which requires bringing together domains that are radically conflicting in conceptual terms. As Turner puts it, they consist of "integrating two or more conceptual arrays as inputs whose frame structures typically conflict in radical ways on vital conceptual relations, such as cause-effect, modality, participant structure, role-value, and so on" (Turner, 2003, p. 117).

In a crucial essay, Turner elaborates on various applications of double-scope stories, discussing how they can be applied in myth, religion, politics, fictional narratives or everyday conversations, demonstrating their utility in conceptuali- 
zing various forms of human experience. One example of double-scope blending embedded in a narrative successfully used in political context which Turner brings forth is that of Seabiscuit, an old, crippled underdog horse that unexpectedly beat the favored War Admiral in a famous race in 1938, just before the beginning of World War II and proved to be a beloved national story, becoming no.1 newsmaker outrunning Hitler or the American president. Turner quotes a scholar commenting on the event over sixty years later who suggests that the lazy, amiable underdog Seabiscuit was much easier to relate to by common Americans than his impertinent and aptly named rival, War Admiral (Turner, 2003, p. 132). The race appeared to turn into a double scope story where the peaceful, underdog American people in the grip of the Great Depression managed to stand up and defeat the stern intimidating war-loving Hitler who at that point already annexed Austria and partitioned Czechoslovakia. The blend was made of two separate stories: the horse race and the political events in Europe at that time. Mapping involved tracing and selecting similarities between the events of both stories and then projecting the complex political story on the easily cognizable race, making up a double-scope blend. In this view of the story, it can clearly be understood as a blend that helps to strengthen the sense of political identity and to fuel nationalist or militarist sentiments.

The story of Christ is another case of an immensely successful double-scope blend, this one indicating the potential of double-scope stories in religious narratives. As Turner suggests, Christ is a hyperblend merging the unsinning divine with the sinful humanity. A carpenter blended with three stories that are itself complicated blends: a sacrificial lamb, bearer of burden and the one punished for sins. Christ's story inspired further blends, as in the Dream of the Rood poem, where the hyperblend Christ is merged with a tree, which thus becomes personified and whose story of being cut down and shaped into a cross mirrors the torments of Christ (Turner, 2003, pp. 128-131).

One literary example of a famous double-scope blend that Turner mentions is the one from Shakespeare's Sonnet 73, where an older man is likened to a tree in autumn that has few yellow leaves left on nearly bare boughs shaking against the cold. Similarly, Turner says, if we see a man dying under a tree in autumn we can treat this image as two separate stories running parallel and then blend it into one, creating a double-scope blend (Turner, 2003, p. 120).

Even though Turner suggests his discussion involves double-scope stories, some of his examples seem to be closer to metaphors than to narratives. Notably the dying man-tree blend and his account of Christ, though the latter clearly functions in a larger context of the biblical narrative. The former involves a comparison of a dying man to a tree in autumn and thus implies a static metaphor, rather than a dynamic narrative. Even if we assumed the blend as composed out of the life 
story of the dying man and an account of the growth and death of a tree that would still not count as a blend of two stories for most narratologists, as a description of a dying tree remains a dynamic description rather than a narrative. Such conflation of narrative and metaphor may be natural for Turner as he sees blending as a fundamental operation underlying both figurative language and narrativity. It is not, however, commonly perceived as such among narratologists, nor is it very intuitive. In fact, the tendency in narrative studies has been to keep narrative and metaphor apart and, thus, I wish to now to turn to the relation between the two.

\section{Narrative and metaphor}

Before the advent of modern narratology, it was perhaps Roman Jakobson who was first to explore the relation between metaphor and metonymy as strictly tied to poetry and prose respectively, noting that the former utilizes the figure of metaphor, which is based on finding similarities and thus the linguistic process of selection, while the latter involves metonymy, which operates along the lines of contiguity, and thus the process of combination (Jakobson, 1956). Jakobson's structuralist approach sees the two as opposing poles of language, tied to completely different thought processes. This line of thought was later developed by David Lodge, who adhered to Jakobson's binary, structuralist distinction, offering a typology of contemporary fiction (Lodge, 1977). Elaborating on the pair, he concluded that poetic metaphor operates according to similarity, selection and substitution, whereas prosaic metonymy is based on contiguity, combination and deletion. For example, the metonymic phrase "keels crossed the deep" involves contiguities between keels and ships and depths of sea which are then deleted (condensed). Lodge also extends the debate by referring to other forms of art. For instance surrealism becomes chiefly metaphoric, whereas cubism metonymic. Drama is overall metaphoric and film metonymic. In spite of this, within a given art, certain techniques may go against the predominant mood: cinematic montage is metaphoric, as it operates on the principle of similarity, while close-up is synecdochic/metonymic. These, however, are seen as localized exceptions to the dominant poles without any significant bearing on the overall relation between metaphor and metonymy.

Apart from the possible reasons for narratology's downplaying of metaphor alluded to earlier, one could also mention the fact that whether that's Jakobson, Lodge or even Turner, they all seem to highlight narrative structure. The heyday of narratological interest in plot and structure ended along with the dying out of purely structuralist paradigm. Since then, narratology has moved to the study of 
discourse, rhetoric and embraced cognitive approaches and plot/structure fell out of favour. In the words of Karin Kukkonen "At the core of narrative inquiry since Aristotle, reconceptualised and refined (sometimes beyond recognition) since, it seems that there might not be a lot left to say about plot" (Kukkonen, 2014).

The structuralist insistence on the binary opposition between metaphor and metonymy on the basis of underlying opposing linguistic processes, makes this approach rather unique in comparison to the whole tradition of rhetoric and to cognitive linguistics where metonymy is seen as a type of metaphor. Though one could argue that prose or film and thus very standard cases of narratives operate close to the metonymic pole of language, it would be rather cavalier to claim narrative is equivalent to metonymy and even less, that as a result is closely tied to metaphor in any strong sense.

As I indicated earlier, narratology in general does not see metaphor and narrative as similar in any interesting sense. For instance, Popova (2015) claims openly against Turner that metaphor and narrative are two fundamental, opposing modes of organizing experience, one based on analogies and associations and another on spatio-temporal causalities and succession. Likewise, Fludernik stresses the separateness of narrative and metaphor as two distinct modes of thinking $(2009$, p. 1), though metaphors undeniably appear within narratives both on a micro and macro level (2009, pp. 73-74), they overall make up an additional discursive level which "can, but need not, be narratologically relevant" (Fludernik, 2009, p. 74). Clearly, metaphor may be local in a narrative or a whole narrative could be a complex metaphor, an allegory, but within narrativity itself, there seems to be no place for metaphor. On the other hand, as she observes certain juxtapositions of scenes and images tend to be metaphorical, as in "a sequence showing workers streaming into the subway followed by another showing images of a flock of sheep being herded along suggests that the workers are sheep" (Fludernik, 2009, pp. 75-76) but sees it something peculiarly cinematic, though it would be "worthwhile investigating whether such strategies are also employed in novels" (Fludernik, 2009, p. 76). All in all, Fludernik claims narrative and metaphor are separate, though she admits in some circumstances narrative events can be linked associatively, thus making up a metaphor, but does not consider it significant. Were we to apply Turner's theory here, it would occur that the two events are linked via the process of double-scope blending, where radically conflicting domains merge and it is then that a complete blended structure of the work comes into existence. Similar observations were made by Edward Branigan in his Narrative Comprehension and Film, where he talks about double causal chains tightly woven together in narratives, yet again effectively leading to a metaphorical blend of parallel plotlines. Elsewhere, he talks about a sequence from Orson Welles' The Lady from Shanghai where three disparate actions are intercut so as to suggest (impossible) causality between a woman 
pressing buttons, door opening with a dying man dragging himself inside and a car crash. This a clear case of events linked not in a strictly causal, but associative, metaphorical way. In fact, Branigan describes it as causality established by means of metaphor, which "functions to describe the nature of the causation" (Branigan, 1992). No broader conclusions are drawn out of the cases discussed by either author.

Outside of narratological mainstream and a little earlier in time, one can find accounts of narrativity and metaphor which are not as declaratively clear cut as in Fludernik or Popova. For example, in his 1984 Reading for the Plot, Peter Brooks claims beginnings and endings of stories are always linked together metaphorically, that is, by means of similarity. What stretches between the beginning and ending is a chain of metonymies moving towards what is adjacent in space and time. Brooks' analysis is clearly limited to $19^{\text {th }}$ century realist fiction when "proper" beginnings and endings were necessary parts of the dominant mode of storytelling. However, it adds more cases to the list of stories where at least some crucial events are linked not only causatively, or metonymically, but associatively, metaphorically. Brooks follows the earlier point made by Todorov about plot being a series of transformations of states of affairs on the basis of tension between similarity and difference. This implies, Brooks holds that the totality of a narrative must operate as a metaphor, for it "brings into relation different actions, combines them through perceived similarities... [and] appropriates them to a common plot" (Brooks, 1984, p. 91) excluding contingence, incident or strict causality.

Brooks' claims are surely too restrictive to serve as a general theory of narrative and plotting. Not all stories are structured this way. In fact, if we were to count ordinary, everyday storytelling in, than most are devoid of a strong, associative link between the inciting event and the resolution. Moreover, many celebrated fictional narratives do not have "proper" endings and resolutions the way $19^{\text {th }}$ century realist fiction does. Still, even though too restrictive for a purely descriptive general theory of a narrative, I believe Brooks' points could be adapted to talk about aesthetic expectations readers or audiences might have about fictional narratives rather than about the content of the narratives themselves. In other words, we standardly expect most fictional narratives to be unified thematically or associatively, even if they fail to be unified in the fashion of realist fiction: by causal chain of events that lead to a resolution of the initial problem. The causal chain resolution might be there, but what in fact is more important is what I'm willing to call aesthetic resolution, that is a sense that events of a narrative are unified and complete in an associative/affective/emotional way, which I believe is close to metaphorical structure or to Turner's blending. In order to elaborate on that I point, I am going to first turn to a rather puzzling passage from Aristotle's Poetics. 


\section{Emotional resolution and associative unity}

But again, Tragedy is an imitation not only of a complete action, but of events inspiring fear or pity. Such an effect is best produced when the events come on us by surprise; and the effect is heightened when, at the same time, they follow as cause and effect. The tragic wonder will then be greater than if they happened of themselves or by accident; for even coincidences are most striking when they have an air of design. We may instance the statue of Mitys at Argos, which fell upon his murderer while he was a spectator at a festival, and killed him. Such events seem not to be due to mere chance. Plots, therefore, constructed on these principles are necessarily the best. (Aristotle, Poetics, IX)

Though the final remarks about Mitys seem to play a crucial role in Aristotle's theory, he does not elaborate on it beyond the passage given above. The causality chain between Mitys' murder and then the murderer's death is highly unclear. Is it mere ancient poetic justice? Is it supernatural intervention of a god or a ghost? Did the murderer cause it to fall on him out of guilt or unwittingly? These questions must be left unanswered and thus a gap in the narrative causal chain is created. Nevertheless, the gap does not seem to be an obstacle for responding emotionally to the narrative and seeing it as complete, even though it is not completeness of cause-effect chains. Aristotle appears to be suggesting that linking events in a cause-effect or probable sequence is the basis of good storytelling and yet events can also be linked not in a strictly causal way without being random or purely accidental. If such a connection is non-causal or improbable with regard to common sense and not accidental at the same time, it must be associational, based on similarity and consequently leaning towards the metaphorical.

Commenting on Aristotle's passage, Velleman (2003) argued it demonstrates that beneath the surface narrative structure of cause-effect or probabilities lies an emotional structure corresponding with the structure of human emotional experience, that is excitation and resolution. This proves, according to Velleman, that the real condition of narrativity is not the causal sequencing of events but the "emotional cadence," their ability to evoke excitation and a relevant resolution, however causally or probably disconnected they may be. Just as in the case of Brooks, I see this as too restrictive for a general theory of narrative (not to mention that emotional cadence might be produced by almost anything, not just stories), but it is helpful in understanding the aesthetic dimension of experiencing stories. Again, if we have aesthetic expectations about narratives, they include that a story be unified in some thematic and emotional sense. This associative unity often is complementary to the standard cause-effect unity, meaning that they 
simultaneously operate together, but there can be cause-effect gaps as in Mitys' story where causal structure is substituted by emotional one, or it can be prominent and foregrounded.

Offering a different, yet complementary to Velleman's approach, response to Mitys' story, Patrick Hogan delves deeper into the associative structure of narratives and formulates theory of aesthetic response to narratives using standard widely accepted cognitive accounts of memory. Specifically, what is germane to the experience of verbal art is the part of long-term memory called semantic memory, or the mental lexicon, which is "a system of circuits that spread throughout long-term memory, encompassing a wide range of information," (Hogan, 1996, pp. 163-194) that includes, apart from definitions, beliefs, attitudes, visual images, memories, ideals, norms, etc. Moreover, just like all other items stored in long-term memory, lexical entries are mainly addressable by means of their content, which means that in order to arrive at them, it is not prerequisite to start with the initial sound of the linguistic representation of a given entry, as in standard dictionaries or encyclopedia. One can access an item through part of the meaning or a referent or through some chain of associations, be it common or highly idiosyncratic.

Various chains and networks of associations and multimodal representations are activated whenever we come across a linguistic utterance, but when experiencing a narrative competently we tend to have some expectations about the richness and depth of the language or images used. As Hogan puts it, we are more inclined towards dallying with the meanings, associations or contexts appearing when in contact with a literary text. It is, then, a form of delectation of suggestions or evocation that are typically linked to a particular theme in an affective way, but this aesthetic suggestiveness is not equivalent to causal unity. Hogan's example of a hamlet on the Ganga is an image that tries to evoke sanctity, peace and purity (Hogan, 1996, pp. 163-194), Turner's double scope-stories also activate various networks of associations that are linked to a particular emotion. The Shakespearean man-tree in autumn blend evokes feeling of sadness over passing and death. Seabiscuit story tries to comfort and motivate, as well as deliver from fear. Christ story attempts at comforting too, along with the feeling of relief, justice and the vision of never-ending well-being. Turner also mentions a double-blend story involving a statue of 16th century Spanish conquistador who had been accused, and perhaps apocryphally, of inflicting severe punishment on rebellious local populations in present day New Mexico, including amputation of right foot. Four centuries later an anonymous groups claiming to be descendants of the harshly punished tribe took credit for cutting off the right foot of the monumental statue of the conquistador in New Mexico (Turner, 2003, p. 128). Just like in Aristotle's example, there is no logical connection between the events in the sense that the 
conquistador was not punished by those who suffered due to his deeds, but it was his symbol that was metaphorically punished. The actual deed was not avenged and there was hardly any causal necessity for the 20th century New Mexicans to mutilate the statue but their double-scope imagination produced an emotionally appealing story that has a metaphoric, associative unity foregrounded, just like the story of imaginary revenge on the man that killed Mitys. Narratives that are successful in triggering aesthetic emotions are structured in such a way as to evoke a network of associations related to a particular emotionally salient theme. The type of unity of a literary work or narrative that is crucial for it being aesthetically (affectively) successful is not just the basic causal or logical unity, but it is a unity and interrelation of the internal parts of a work (its aesthetic design) that is, again, the unity of chains of associations linked to particular emotions.

\section{Conclusion}

All in all, if we have aesthetic expectations about a narrative, then we expect it to be structured in a thematically unified way so as to trigger relevant emotions. There seem to be, thus, two structures pertinent to the narrative sequence of events: the causal or probable structure (roughly, metonymic) and the associative structure (roughly, metaphorical). These can operate in a complementary and simultaneous fashion, though in some stories, the associative link can substitute the causal one in varying degrees. Further, not only can events be linked associatively, by means of tracing similarities between them, but as the above discussion demonstrates, the very act of linking them in such a way is reminiscent of double-scope blending, as one imputes a connection between events where there cannot be any apart from that of likeness. As a result, construing a complete fictional narrative involves double-scope blending, too, since one brings together the causal structure of events with the associative one into a single, unified domain of a work. I should emphasize that I am not making any general points about blending, as in corroborating or questioning if it is a fundamental human thought process. My argument is merely that it appears double-scope blending plays a role in cognizing the associative structure of a narrative and its relation to the causal structure bringing about the complete narrative. Neither am I making a point that can be easily inferred from blending theory that there is a deeper relation (of perhaps reduction or even identity) between metaphor and narrativity in any interesting way. My modest claim is that, perhaps counterintuitively, the process of metaphor can link events strengthening associational dimension to narratives which in turn potentially enhances their affective and aesthetic potential. 


\section{References}

Aristotle. Poetics. Online version at http://classics.mit.edu/Aristotle/poetics.html Branigan, E. (1992). Narrative Comprehension and Film. New York: Routledge. Brooks, P. (1984). Reading for the Plot. New York: A. Knopf.

Fauconnier, G. \& Turner, M. (2003). Cconceptual blending, form, and meaning. Recherches en Communication: Sémiotique Cognitive, 19, 57-86.

Fauconnier, G. \& Turner, M. (2008). The origin of language as a product of the evolution of double-scope blending. Behavioral and Brain Sciences, 31(5), 520-521.

Fludernik, M. (2009). An Introduction to Narratology. New York: Routledge.

Hogan, P. (1996). On Interpretation: Meaning and Inference in Law, Psychoanalysis, and Literature. Athens: University of Georgia Press.

Jakobson, R. (1956). Two aspects of language and two types of aphasic disturbances. Fundamentals of Language, 1, 69-96.

Kukkonen, K. (2014). Plot. In K. Kukkonen, P. Hühn, J. C. Meister, J. Pier, \& W. Schmidt (Eds.), The Living Handbook of Narratology. Hamburg: Hamburg University. http:// www.lhn.uni-hamburg.de/article/plot [accessed: 25.03 2019].

Popova, Y. (2015). Stories, Meaning, and Experience: Narrativity and Enaction. New York: Routledge.

Schneider, R. \& Hartner, M. (Eds.). (2012). Blending and the Study of Narrative. Approaches and Aplications. Berlin: De Gruyter.

Turner, M. (1998). The Literary Mind. Oxford: OUP.

Turner, M. (2003). Double-scope stories. In D. Herman (Ed.), Narrative Theory and the Cognitive Sciences, (pp. 117-143). Stanford: CSLI.

Turner, M. (2008). The mind is an autocatalytic vortex. Online article available at http:// ssrn.com/abstract $=1274225$

Velleman, J. D. (2003). Narrative explanation. The Philosophical Review, 112(1), 1-25. 